\title{
Effect of BMI and gender on stress and anxiety - A physiological insight
}

\author{
Sureka ${ }^{1}$, Abeetha. $\mathrm{S}^{2, *}$, Brinda. $\mathrm{S}^{3}$, Ganesh .M${ }^{4}$, Poovarajan ${ }^{5}$ \\ ${ }^{1}$ Professor, ${ }^{2,3,5}$ Assistant Professor, ${ }^{4}$ Professor and HOD, Dept. of Physiology, A.C.S. Medical College and Hospital, Chennai, \\ Tamil Nadu, ${ }^{5}$ D.B. Jain College, Chennai, Tamil Nadu, India \\ *Corresponding Author: Abeetha. $\mathrm{S}$ \\ Email: subramanian.or.abee@gmail.com
}

Received: $30^{\text {th }}$ July, 2018

Accepted: $30^{\text {th }}$ August, 2018

\begin{abstract}
Introduction: There are various stressors that a student will encounter during their initial college days and our focus is to assess if gender and BMI have any effect on the stress and anxiety experienced by students.

Materials and Methods: The questionnaire based study was conducted in a private medical college. 172 students doing their paramedical course participated in the study. Anxiety and stress were assessed using Generalised Anxiety Disorder (GAD-7) and Cohens stress scale. BMI was calculated using anthropometric data.

Results: The prevalence of low, moderate and high stress among students was $15.7 \%, 34.3 \%$ and $50.0 \%$ respectively. Similarly $29.1 \%$ students showed mild anxiety, $36 \%$ and $34.9 \%$ had moderate and severe anxiety. $57 \%$ females showed high stress. Anxiety values was similar among both genders. There was no association between stress and BMI. But underweight students showed more anxiety than others.

Discussion: Study shows a wide prevalence of stress and anxiety among students. BMI also acts as a contributing factor for stress. Priority must be given for psychosocial well being of students as it reflects in their academic excellence and social behavior.
\end{abstract}

Keywords: Anxiety, Adolescence, BMI, Stress.

\section{Introduction}

Stress and anxiety are two major determinants of success and performance in students who have just entered professional institution. For a fresher entering college hectic schedule due to change in timings, academic workload and demands of the new atmosphere acts as a stressor. Actual stress occurs due to interaction between stressor and the individual perception to that stress. ${ }^{1}$ Problems arise when demands on an individual exceeds the persons capacity to handle it. $^{2}$ There is a wide belief that clinical depression, cardiovascular diseases and cancer are aggravated by stress and prolonged stress can lead to dementia and other toxic states. Prevalence of stress varies with gender $^{3}$ as academic pressures acts as a predominant stressor among female students. Along with gender even age of the student can alter the prevalence of stress as students who are older handle pressurized situations better. Lack of support creates a psychological stress and this can cause profound changes on BMI either due to over eating or starvation. With literature revealing wide prevalence of stress and anxiety which gets aggravated by age, gender and BMI we aim to assess the influence of these factors on stress and anxiety among first year college students.

\section{Objectives}

1. To assess the prevalence of stress and anxiety among paramedical students.

2. To measure BMI of the students and relate stress and anxiety with BMI, age and gender.

\section{Materials and Methods}

After obtaining Institutional Ethical committee approval the study was explained and volunteers were selected as study participants. Informed consent was obtained. Complete family history was recorded. Students in age group 17-21 years were included in the study. Students who were already under medications were excluded. The self administered questionnaires for stress, Cohen's stress scale (Cohen 2007) and Generalised Anxiety disorder-GAD-7 were distributed. ${ }^{5}$ The Perceived Stress Scale (PSS) of Sheldon Cohen, the most widely used psychological instrument for measuring the perception of stress is a measure of the degree to which situations in one's life are appraised to be stressful. The scale included ten questions on the students' behavior on handling unexpected situations, situations which made them highly irritable and situations that made them feel positive and confident. Items were designed to find how unpredictable, uncontrollable, and overloaded respondents find their lives. The scale also includes a number of direct queries about current levels of experienced stress. The questions in the PSS ask about feelings and thoughts during the last month. Each item is rated on a 5-point scale ranging from never to almost always. ${ }^{4}$ Positively worded items are reverse scored, and the ratings are summed, with higher scores indicating more perceived stress. Scores around 13 are considered average and 20 or higher are considered high stress. Anxiety questionnaire had seven questions regarding situations when they had trouble relaxing or when they were worrying too much or feeling annoyed or feeling 
something awful might happen. Students were asked to mark scores on the frequency of experiencing these symptoms. Details regarding age, gender, medical history was recorded from students. Anthropometric details such as body weight and height was recorded. ${ }^{6}$

Body Weight: A digital weighing scale was used to measure body weight with an accuracy of $+100 \mathrm{~g}$. Subjects were weighed without their shoes. Height: Standing body height was measured without shoes to the nearest $0.5 \mathrm{~cm}$ with the use of height stand with shoulders in relaxed position and arms hanging freely.

Body Mass Index: BMI was calculated as body weight in kilograms divided by square of body height in meters. Those subjects with BMI $>25$ were categorized as obese and those with BMI $<25$ as nonobese.

\section{Results}

The data was entered and analysed by using SPSS software. Chi square test was used to compare proportions for the groups. Mean age of the students was $19 \pm 2$ years. Our results show a wide prevalence of stress and anxiety among first year students (Fig. 1) and it was found that while $15.7 \%$ students show low prevalence of stress, $34.3 \%$ and $50 \%$ exhibited mild and severe forms of stress. Mean perceived stress observed was $20.47 \pm 6.04$. Similarly prevalence of anxiety (Fig. 2) was found to be $29.1 \%, 36 \%$ and $34.9 \%$ in mild, moderate and severe forms respectively. Anxiety disorder grading showed a mean of 9.16 4.69 . Pearson's coefficient of Correlation between gender and stress showed significance $(\mathrm{p}<0.012)$. It was found that females experienced high stress (53.2\%) when compared to males $(36 \%)$. But males showed a higher level of mild and moderate stress. $48.8 \%$ males and $33 \%$ females showed moderate stress. On analysis of correlation between gender and anxiety, (Fig 3 \& 4) $33.7 \%$ males showed mild anxiety, $30.2 \%$ moderate and $36 \%$ severe anxiety. In females $22.3 \%$ had mild $39.9 \%$ moderate and $37.8 \%$ severe anxiety. On analysis of stress and anxiety with BMI, (Fig 5 \& 6) it was found that all participants experience some form of stress with obese showing more stress when compared to underweight. Anxiety levels were higher in underweight when compared with normal. Correlation of age with stress and anxiety showed no significance ( $p>0.05$ ), as wide prevalence of stress and anxiety was seen among all age groups.

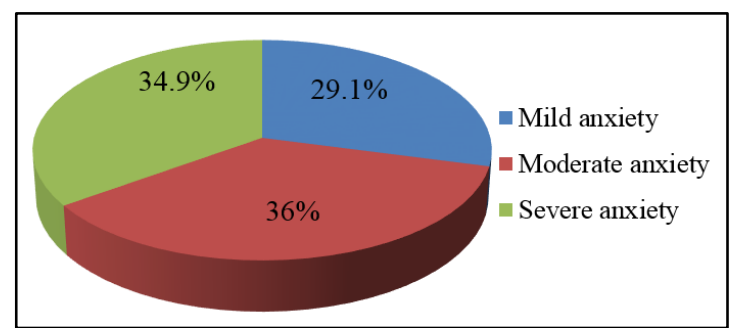

Fig. 1: Prevalence of stress

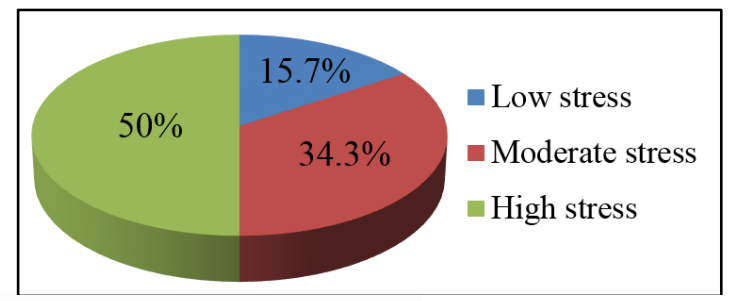

Fig. 2: Prevalence of anxiety

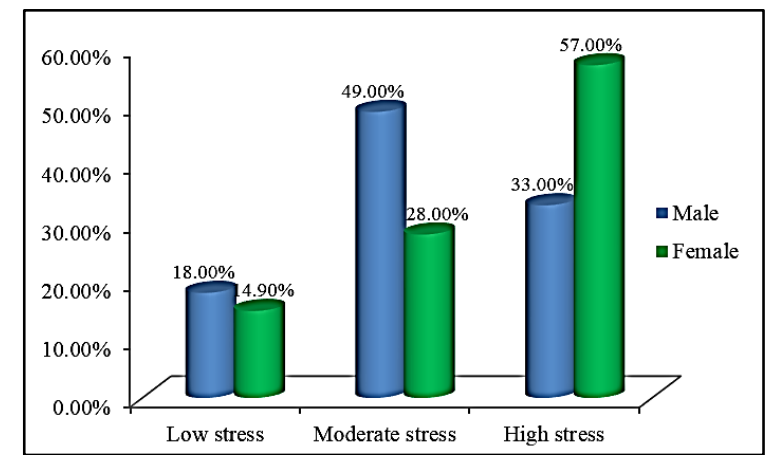

Fig. 3: Correlation of stress with gender

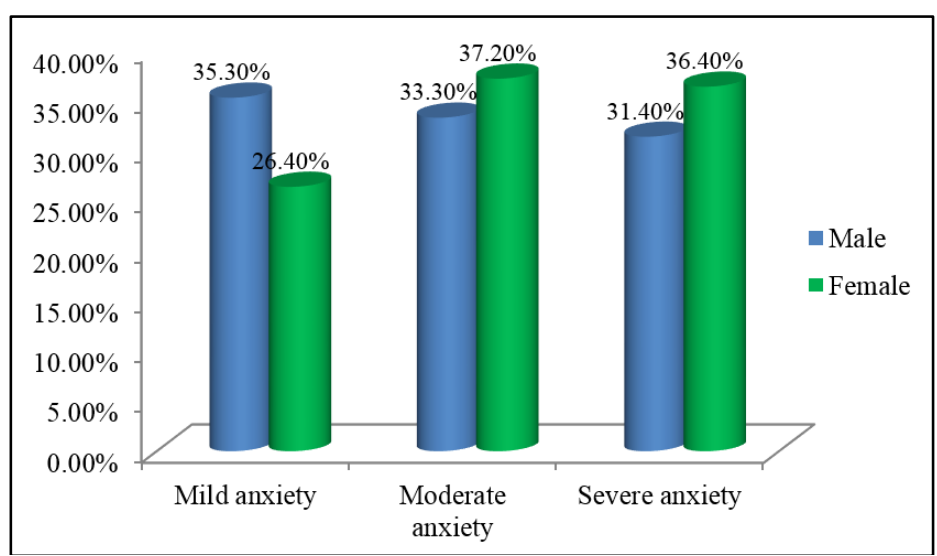

Fig. 4: Correlation of anxiety with gender 


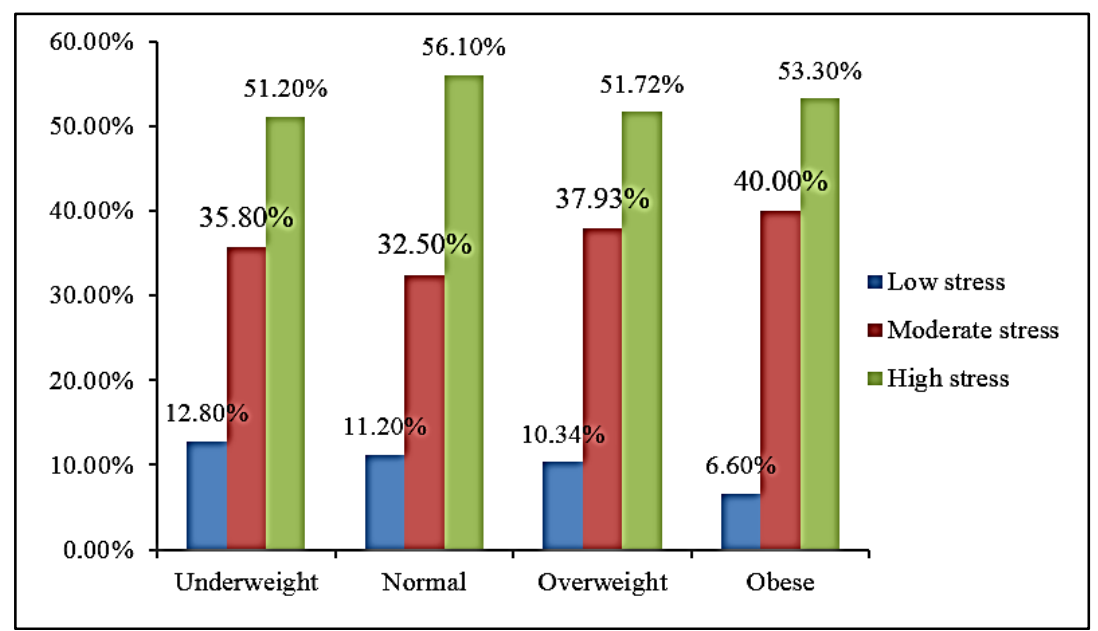

Fig. 5: Association of stress with BMI

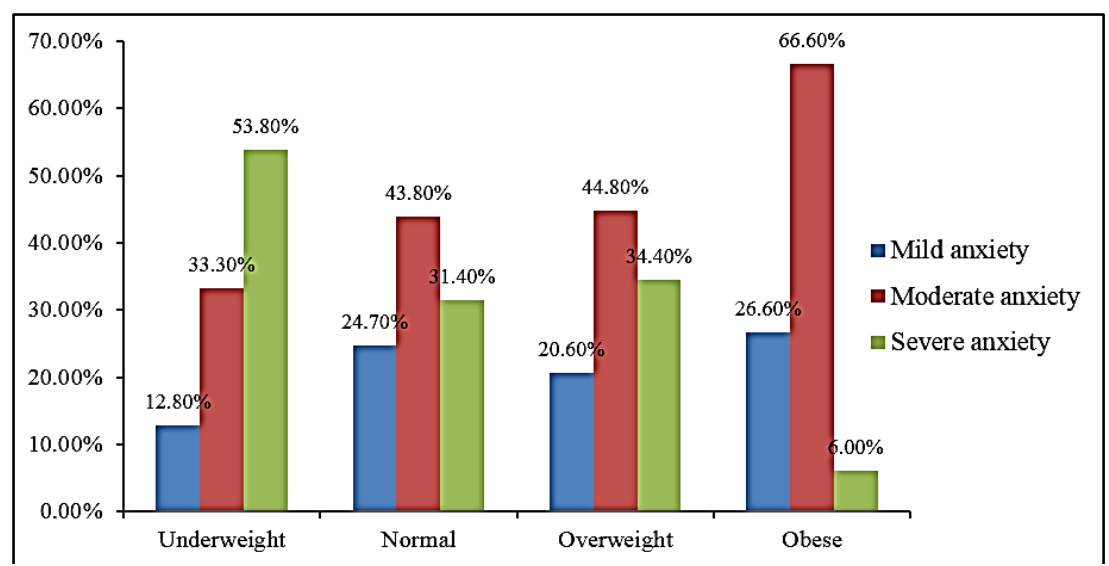

Fig. 6: Association of anxiety with BMI

\section{Discussion}

Students of this generation are exposed to more stressors and need guidance to overcome them. Stress can be either related to academics, social factors or new environment. $^{7} 73 \%$ of first year students had stress and it has been found that students who are more academically oriented faced greater stress. Previous studies also have shown that students face increased stress level in first year than in subsequent years of education. ${ }^{8,9}$ Financial stress of the family adds up to the stress of some students which reflects in their social behavior. ${ }^{10}$ Age of the student in a peer group acts a deciding factor in few conditions as older student find it easier to get solutions for issues in a logical manner. Our study results indicated no association between age and stress as stress was prevalent among all age groups, even though there have been studies that show that older students usually handle stress better. Increased stress in younger age group may be due to new responsibilities, increased work load, new culture and alternate ways of thinking. Academic stress has been a subject of research for a long time and can be due new syllabus, lack of understanding of concepts and inefficient time management skills. ${ }^{11}$ Women in general have been regarded to experience more stress and anxiety. Stress varied with gender and increases with education. ${ }^{12,13}$ Males have shown to cope up with stress and anxiety much better than girls due to their involvement in leisure activities. ${ }^{3}$ Similar pattern was observed in our study with significant relation between stress and females. Another very important contributing factor for stress and anxiety is being either obese or underweight. Even though our study did not reveal any significant association between stress and BMI, Canadian studies have shown that job stress has a positive relation with BMI as stress can induce students either to overeat or can cause suppression of hunger. Stress can cause an increase in cortisol secretion which is associated with weight gain ${ }^{14}$ and lack of strategies to cope up with stress is also associated with increased stress. ${ }^{15}$ Only one study suggested an inverse association between a coping strategy (i.e., confrontive coping) and BMI in 180 women. ${ }^{16}$ Knowing the actual cause of stress will help create stress management systems in the college which will do lot of good for the students. Stress relieving practices like yoga, meditation and spirituality will help reduce the levels of anxiety, stress and depression. ${ }^{17}$ Parental support and guidance plays a very important role in adolescent age. Periodic interaction of students with faculty members will help 
the faculty to understand each student and will help to improve the academic performance and reduce stress level of student to a great extent.

\section{Acknowledgements}

To the college management for allowing us to do this study and all students who cooperated with us to finish this work within the time frame.

\section{References}

1. Gajalakshmi G, Kavitha U, Anandarajan B, Chandrasekar M. A study to analyze various factors contributing to stress in first year mbbs students during examination. International Journal of Biomedical and Advance Research. 2012;03(09).

2. Cohen S, Kamarck T, Mermelstein R. A global measure of perceived stress. J Health Soc Behav. 1983;24:385-96.

3. Misra. R, McKean, Michelle. College students' academic stress and its relation to their anxiety, time management, and leisure satisfaction. American Journal of Health Studies. 2000:41-51.

4. Sheldon Cohen, Denise Janicki-Deverts, Gregory E. Miller. Psychological Stress and Disease.

JAMA. 2007;298(14):1685-1687.

5. Spitzer RL, Kroenke K, Williams JBW, Löwe B. A Brief Measure for Assessing Generalized Anxiety Disorder. The GAD-7. Arch Intern Med. 2006;166(10):1092-1097.

6. Srinivasan K, Vaz M, Sucharita S. A Study of stress and autonomic nervous function in first year undergraduate medical students. Ind J Physiol Pharmacol. 2006;50:25764.

7. Supe AN. A study of stress in medical students at Seth GS Medical College. J Postgrad Med. 1998;44:1-6.

8. Guthrie E, Black D, Bagalkote H, Shaw C, Campbell M, Creed F. Psychological stress and burn out in medical students: a prospective longitudinal study. J R Soc Med.1998;91:237-243.

9. Saipanish R. Stress among medical students in a Thai medical school. Med Teach. 2003;25:502-506.
10. Mariana Souto-Manning Kevin J. Swick. Teachers' Beliefs about Parent and Family Involvement: Rethinking our Family Involvement paradigm. Early Childhood Edu J. 2006;34(2):187-193.

11. Abdulghani HM. Stress and depression among medical students: A cross sectional study at a medical college in Saudi Arabia. Pak J Med Sci. 2008;24:12-7.

12. Johari $A B$ and I Noor Hassim. Stress and coping strategies among medical students in National University of Malaysia, Malaysia University of Sabah and University Kuala Lumpur Royal College of Medicine Perak. Jurnal Kesihatan Masyarakat. 2009;15(2):106-115.

13. Katsuharu Nakazato, Yoshiko Shimonaka. The Japanese State-Trait Anxiety Inventory: Age and Sex Differences. Percept mot skills. 1989;69(2):611-7.

14. Nuran Bayram, Nazan Bilgel. The prevalence and sociodemographic correlations of depression, anxiety and stress among a group of university students. Social Pscychiatry and Psychiatric Epidemiology. 2008;43(8):667-672.

15. Ranjni Soni. Level of stress in first year medical student. Indian Journal of behavioural Sciences. 2007 (2).

16. Azagba S, Mesbah F. Sharaf. The relationship between job stress and body mass index using longitudinal data from Canada. Int. J of Public Health. 2012;57(5):807815.

17. Shauna L. Shapiro, Gary E. Schwartz, Ginny Bonne Effects of Mindfulness-Based Stress Reduction on Medical and Premedical Students. J of Behavioural Med. 1998;21(6).

How to cite this article: Sureka, Abeetha .S, Brinda .S, Ganesh .M, Poovarajan. Effect of BMI and gender on stress and anxiety - A physiological insight. Indian J Clin Anat Physiol. 2018;5(4):464-467. 